\title{
No scalpel vasectomy: a cross-sectional study of knowledge, attitude and practice of gynaecologists
}

\author{
Girish P. Godbole ${ }^{1 *}$, Gauri A. Oka ${ }^{2}$
}

\begin{abstract}
${ }^{1}$ Department of Obstetrics and Gynaecology, ${ }^{2}$ Department of Research, Deenanath Mangeshkar Hospital and Research Centre, Pune, Maharashtra, India
\end{abstract}

Received: 17 January 2019

Accepted: 11 February 2019

\author{
*Correspondence: \\ Dr. Girish P Godbole, \\ E-mail: gpgodbole@gmail.com
}

Copyright: (c) the author(s), publisher and licensee Medip Academy. This is an open-access article distributed under the terms of the Creative Commons Attribution Non-Commercial License, which permits unrestricted non-commercial use, distribution, and reproduction in any medium, provided the original work is properly cited.

\begin{abstract}
Background: In spite of no scalpel vasectomy (NSV) being cheaper and safer, female sterilisations account for the majority of sterilisations performed worldwide. Research has focussed more on the "demand" and less on the "provider" side. Gynaecologists can be front-runners for the cause of population control in India. Hence, authors decided to estimate the knowledge of gynaecologists, their attitude and prevalent practice of NSV.

Methods: Cross-sectional study. Interviewer-administered questionnaire used for face-to-face data collection from gynaecologists registered with the Pune Obstetric and Gynecological Society.

Results: Out of 447 gynaecologists, 158 (35.3\%) were males and 289 (64.7\%) females. Mean age was 46.3 years \pm 12.1 years, (range $24-80$ years). Only $14(3.1 \%)$ were trained in performing NSV. Only a minority knew about type of anaesthesia used (1.8\%) and number of accesses needed (48.1\%) for NSV. Only $40.7 \%$ and $18.1 \%$ knew about time to resume sexual activity and number of ejaculations to be covered by additional contraceptives after NSV respectively. More than half $[258(57.7 \%)]$ were willing to undergo training in NSV. Among those unwilling for training, female and older gynaecologists $(\geq 40$ years) significantly outnumbered male and younger gynaecologists (76.5\% Vs. $23.5 \%$; $\mathrm{p}=0.000$ and $78.8 \%$ Vs. $21.2 \%$ respectively; $\mathrm{p}=0.000)$. Majority $(79.9 \%)$ referred a couple willing for NSV to surgeons or urologists or advised female sterilisation (17\%).

Conclusions: Knowledge of gynaecologists about NSV was inadequate. Minority were trained in performing NSV. Male and younger gynaecologists were willing to undergo training in NSV. Most preferred practices were referring couples elsewhere or advising female sterilisation.
\end{abstract}

Keywords: Attitude, Gynaecologists, Knowledge, No scalpel vasectomy, Practice

\section{INTRODUCTION}

Since the advent of vasectomy, various attempts at its improvisation have taken place, namely, making the procedure safer, easier to perform, more effective and more acceptable. The technique of no-scalpel vasectomy (NSV) was developed by Dr. Li Shunqiang in 1974 mainly to increase vasectomy use in China and also to remove the fear of incision from men's minds. ${ }^{1}$ Most of the complications that arise from the traditional incision procedure, particularly bleeding, hematoma and infection can be attributed to the surgical incision. ${ }^{1}$ No-scalpel vasectomy, being a less invasive approach, avoids blind dissection, which in turn helps prevent tissue trauma and blood vessel injury. Thus, NSV has a low surgical complication rate, especially hematoma and infection. ${ }^{2,3}$ Many studies have been conducted so far to explore reasons why female sterilisations outnumber male sterilisations. $^{4-6}$ These studies have focused upon knowledge, attitudes, perceptions and consequently, behaviour of men and couples who opt for female sterilisation as a preferred method of permanently 
limiting family size. The reasons for vasectomy being unpopular include, among others, "lack of knowledge and misconceptions about the procedure (being equated with castration)", "men fear being shamed and taunted by community members, who might refer to them as infertile", "fear of a bad name for the woman who conceives post her husband's vasectomy", belief that female sterilisation has higher success rate of reversibility, fear of incision, and fear of loss of potency and loss of sexual drive. ${ }^{4-8}$ Authors feel that gynaecologists are in a perfect position to create and increase awareness and thereby, the demand for male sterilisation. However, in spite of NSV being a cheaper and safer option which involves lesser morbidity and a greater success rate $(>99 \%)$, female sterilisation is found to account for the majority of sterilisations being performed across the world. ${ }^{7}$ The reasons for this could range from gynaecologists' lack of expertise in performing the procedure to perceived lack of patient compliance. Through our city-wide study, authors decided to assess the knowledge, attitude and practice of NSV among gynaecologists.

\section{METHODS}

This was a cross-sectional study conducted in the city of Pune in western India over a period of 1 year between 2016 and 2017. A list of 793 gynaecologists registered with The Pune Obstetric and Gynecological Society (POGS) was obtained.

\section{Exclusion criteria}

- 160 names had to be excluded (those who had expired or had relocated outside India).

- 95 refused consent and 91 could not be reached even after multiple attempts within a reasonable time frame.

Hence, data was collected from 447 gynaecologists across Pune city. Gynaecologists were initially approached telephonically to explain the nature of our survey and seek consent to participate in the study. Written informed consent was provided by participating gynaecologists. Those who consented were requested for an appointment with trained data collectors. Researchermade questionnaire was administered to be filled in on the spot. Results were analyzed using SPSS (version 20) for Windows (SPSS Science, Chicago, IL, USA). Data is described in the form of mean +/- SD for continuous data and in the form of percentage and proportions for categorical data. $\mathrm{P}$-values of $<0.05$ have been considered significant. To examine the associations between qualitative/quantitative variables, chi-square test has been used.

\section{RESULTS}

There were 158 (35.3\%) male and 289 (64.7\%) female gynaecologists. Minimum age was 24 years and maximum 80 years, with a mean age of $46.3 \pm 12.1$ years. It was observed that $195(43.6 \%)$ participants had $\geq 20$ years of practice, $124(27.7 \%)$ had between 10 and 20 years of practice and $128(28.6 \%)$ had less than 10 years of practice. As regards number of female sterilisation surgeries performed, majority $(76 \%)$ had performed between 100 to more than 1000 female sterilisations, while $24 \%$ had performed less than 100. Almost all $(92.2 \%)$ gynaecologists had never performed NSV, but $81.4 \%$ claimed to have ever performed a traditional vasectomy. It was found that mean number of tubectomies performed by male gynaecologists was significantly more as compared to female gynaecologists (2076 Vs. 639; p=0.009). Similarly, male gynaecologists had performed significantly more traditional vasectomies as compared to their female counterparts (32 Vs. 4; $\mathrm{p}=0.003)$. Out of $447,14(3.1 \%)$ gynaecologists (11 male and 3 female) said they were trained in performing NSV.

\section{Regarding knowledge about NSV}

When asked to expand the abbreviation "NSV", 393 $(87.9 \%)$ gynaecologists were able to answer correctly as compared to $54(12.1 \%)$ who either gave answers other than "Non/No Scalpel Vasectomy" or did not know what NSV stood for. Out of the 447, 211 (47.2\%) gynaecologists had never seen NSV being performed. There were $270(60.4 \%)$ gynaecologists who admitted to not knowing the exact steps of the procedure. Only a minority of participants provided correct answers to questions regarding knowledge about various aspects of NSV such as "type of anaesthesia used" (1.8\%), "number of accesses needed to perform NSV" (48.1\%), "number of ejaculations to be covered by additional contraceptives after NSV" (18.1\%) and knowledge about "facilities in Pune providing training in NSV" $(13.2 \%)$. Some knowledge parameters are depicted in Table 1.

Table 1: Knowledge of participants regarding post NSV details $(n=447)$.

\begin{tabular}{|l|l|}
\hline $\begin{array}{l}\text { Knowledge parameter } \\
\text { (expected answer) }\end{array}$ & $\begin{array}{l}\text { Correct answer } \\
\text { n (\%) }\end{array}$ \\
\hline $\begin{array}{l}\text { No. of days to resume routine } \\
\text { activities after NSV (2) }\end{array}$ & $300(67.1)$ \\
\hline $\begin{array}{l}\text { No. of days to resume sexual activity } \\
\text { NSV (7) }\end{array}$ & $182(40.7)$ \\
\hline $\begin{array}{l}\text { No. of days of use of additional } \\
\text { contraceptive methods after NSV (3 } \\
\text { months) }\end{array}$ & $316(70.7)$ \\
\hline $\begin{array}{l}\text { No. of ejaculations to be covered by } \\
\text { additional contraceptives after NSV } \\
\text { (24) }\end{array}$ & $81(18.1)$ \\
\hline
\end{tabular}

Correct answers to knowledge-related questions such as "when can a couple resume sexual activity after NSV" and "what is the current prevalence of use of NSV in Pune" were also provided by a minority of participants only $(40.7 \%$ and $13 \%$ respectively). When asked to choose correctly between female and male sterilisation, 
higher failure rate was attributed to male sterilisation by 259/447 (57.9\%) participants. Opinion was divided regarding whether sex life after NSV was affected, with $398(89 \%)$ gynaecologists opining that a couple's sex life remains unaffected after NSV. It was found that 94/447 (21\%) gynaecologists had no knowledge about where to refer a man for NSV. Regarding knowledge about training facilities in Pune, it was found that $388(86.8 \%)$ gynaecologists had no idea about the same. The compensation provided by the government for NSV acceptors and providers was only known to $10(2.2 \%)$ and $14(3.1 \%)$ participants respectively.

\section{Regarding attitude}

A majority of the participants $(358 / 447,80.1 \%)$ displayed a positive attitude towards NSV saying that they thought NSV was both, safer and more effective as compared to female sterilisation. Reasons thought were "noninvasive" (18.3\%), "safe/low risk procedure" (36\%) and "advantage of local anaesthesia" (15\%). When asked if they would be willing to undergo training if offered a chance, it was found that more than half of the gynaecologists $(258 / 447,57.7 \%)$ were willing. The reasons cited were "to upgrade their knowledge by acquisition of an additional skill" (39.8\%) and being "convinced that NSV was a better option when compared to female sterilisation" (14.1\%). Ten gynaecologists said that since they were already trained, they did not wish to undergo training again.

Table 2 depicts differences in attitudes of male and female gynaecologists towards undergoing training in NSV. Among the reasons for willingness for training, there was no statistically significant difference between male and female gynaecologists.

Table 2: Comparison of reasons for willingness and refusal to undergo NSV training between male and female gynaecologists $(n=437)$.

\begin{tabular}{|c|c|c|c|c|}
\hline Reasons & Male n (\%) & Female n (\%) & Total n (\%) & P value \\
\hline \multicolumn{5}{|l|}{ For willingness for training } \\
\hline Acquire additional skill & $79(44.4)$ & $99(55.6)$ & $178(100)$ & \multirow{4}{*}{ NS } \\
\hline Convinced NSV is a better option & $25(39.7)$ & $38(60.3)$ & $63(100)$ & \\
\hline Concerned of losing patients if referred elsewhere & $4(26.6)$ & $11(73.4)$ & $15(100)$ & \\
\hline Can’t say & $2(100)$ & $0(0)$ & $2(100)$ & \\
\hline \multicolumn{5}{|l|}{ For refusing training } \\
\hline Nearing end of career/not interested & $30(28.6)$ & $75(71.4)$ & $105(100)$ & \multirow{5}{*}{0.000} \\
\hline Perceived poor patient acceptance of NSV & $1(7.7)$ & $12(92.3)$ & $13(100)$ & \\
\hline Being a female gynaecologist & $0(0)$ & $36(100)$ & $36(100)$ & \\
\hline Prefer to refer to a surgeon & $6(40)$ & $9(60)$ & $15(100)$ & \\
\hline Practice obstetrics/foetal medicine/IVF only & $5(50)$ & $5(50)$ & $10(100)$ & \\
\hline
\end{tabular}

Table 3: Practices of gynaecologists if a couple wants NSV (n=447).

\begin{tabular}{|c|c|c|c|c|}
\hline \multirow{2}{*}{ Parameter } & \multicolumn{2}{|c|}{ Practice of } & \multirow{2}{*}{ Total } & \multirow{2}{*}{ P value } \\
\hline & Male gynaecologists & Female gynaecologists & & \\
\hline Perform NSV & $11(78.6)$ & $3(21.4)$ & 14 & NS \\
\hline Refer elsewhere & $122(34.2)$ & $235(65.8)$ & 357 & 0.003 \\
\hline Advise female sterilisation & $25(32.9)$ & $51(67.1)$ & 76 & 0.003 \\
\hline
\end{tabular}

However, among those who were unwilling for training, it was found that reasons such as "being almost at the end of their career" $(71.4 \%)$, perceived poor patient acceptance of NSV $(92.3 \%)$, and preference of referring to a surgeon $(60 \%)$ were significantly more prevalent among female gynaecologists $(\mathrm{p}<0.001)$. Among those unwilling for training, female and older gynaecologists ( $\geq 40$ years) significantly outnumbered male and younger gynaecologists $(76.5 \%$ Vs. $23.5 \%$; $\mathrm{p}=0.000$ and $78.8 \%$ Vs. $21.2 \%$ respectively; $\mathrm{p}=0.000)$. Out of 289 female gynaecologists, $36(12.5 \%)$ perceived that "being a woman" was a limiting factor and thus, were unwilling for training. Almost 50\% (223/447) gynaecologists felt that training in NSV should be included in both undergraduate, as well as, postgraduate medical education.

\section{Regarding practice}

Reasons for not advising NSV were stated by 120 (26.8\%) gynaecologists. They included "It doesn't occur to me", "I do not do it myself", "I do not know where to refer for NSV", and "I am confident performing female sterilisation only". When posed with the question "What do you do when a couple is willing for NSV?" a majority, that is, $357(79.9 \%)$ gynaecologists stated that they 
referred the patient "elsewhere". Among these, as seen in Table 3, the proportion of female gynaecologists was found to be significantly greater than male gynaecologists (65.8\% Vs. $34.2 \%, \mathrm{p}=0.003)$.

Only a very small minority of $14(3.1 \%)$ gynaecologists said that they performed NSV themselves. Among those who advised female sterilisation, again, female gynaecologists significantly outnumbered their male counterparts (67.1\% Vs. $32.9 \%$ respectively, $p=0.003)$.

As regards practice of referral, it was found that majority of the gynaecologists $(210,46.7 \%)$ referred men to surgeons or urologists, followed by 103 (23\%) who referred them to a nearby government hospital (Figure 1).

In response to the question regarding practice of offering the option of long-term temporary contraception, $71.8 \%$ (321/447) gynaecologists said that they always talked about it before arriving at the decision of a permanent sterilisation procedure. Vasectomy, but not necessarily $\mathrm{NSV}$, was found to be advised in special situations like contraindications for female sterilisation by $93.3 \%$ (417/447) participants.

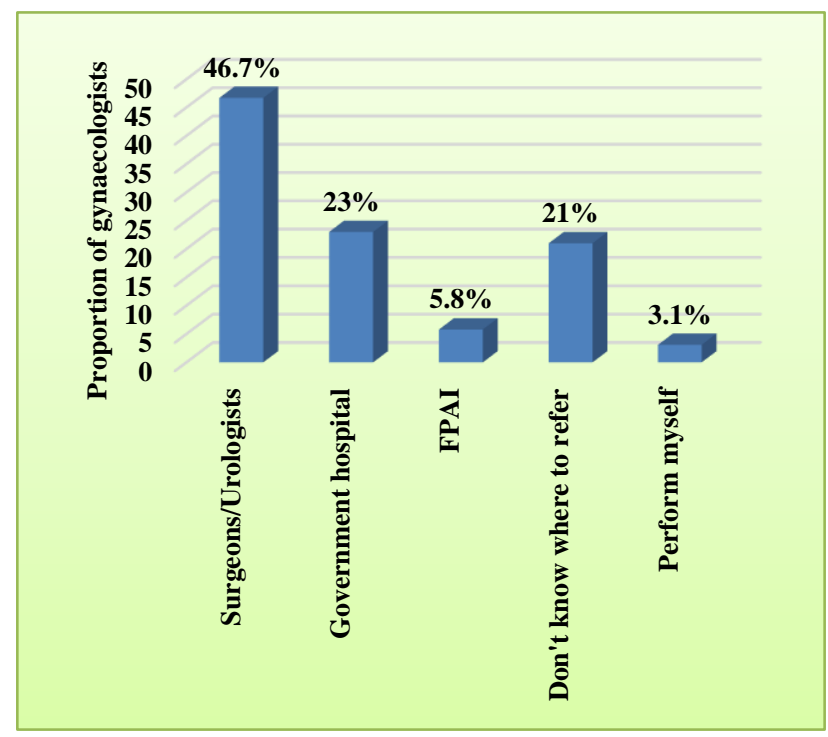

(FPAI: Family Planning Association of India)

\section{Figure 1: Practice of referral in case patient requests for NSV.}

It was the routine practice of $62.2 \%$ (278/447) gynaecologists to discuss the issue of "regret" before a permanent sterilisation procedure. When gynaecologists were asked about what their preferred male profile for would be advising NSV, almost all preferred not to consider wife's education, couple's occupations, rural or urban residence, caste or religion before advising NSV.

However, education of the male partner of $12^{\text {th }}$ standard or more was a preferred criterion by 96 (21.5\%) gynaecologists.

\section{DISCUSSION}

To the best of our knowledge, this is the first study of its kind from India, where gynaecologists have been interviewed to determine their knowledge, attitude and practice regarding no scalpel vasectomy. The results reveal inadequacy of knowledge about NSV among gynaecologists. Also, practice of performing NSV was almost non-existent. However, a majority of the gynaecologists were willing to undergo training in NSV and felt that it was a safer and more effective option when compared with female sterilisation.

In 1992, the technique of NSV was introduced in India to increase the participation of men in family planning. ${ }^{6}$ According to the 2015-2016 data published by National Family Health Survey - 4 (NFHS-4) for Pune, among the currently used family planning methods by married women (age 15-49 years), female sterilisation accounted for $55.5 \%$ while male sterilisation for $0 \% .^{9}$ The national statistic for the same period also revealed extremely poor uptake $(0.3 \%)$ of male sterilisation services as a family planning method (NFHS-4 India, 2015-16). ${ }^{10}$ Authors believe that accurate knowledge and positive attitude towards NSV among providers are key determinants of effective client-provider communication about NSV. Inaccurate or incomplete knowledge of health care providers (community health workers) has shown to adversely affect the ability to advise clients about vasectomy. ${ }^{11}$ This has led to unwillingness by couples to consider vasectomy as an option for limiting family size. ${ }^{7}$ Studies which look at provider issues surrounding NSV are few and limited either to the Western world setting or to the community health worker level in India. ${ }^{7,11-13}$ However, Present study highlights the astounding fact that expert caregivers had almost similar misconceptions about NSV as those expressed by community health workers. Present study shows the lack of accurate knowledge among gynaecologists, especially regarding post-NSV counselling. Not all knew that additional contraceptive cover was required for three months after NSV. Similarly, in the study by Mahapatra et al, only $29.5 \%$ community health workers knew this correctly. ${ }^{11}$ Ebeigbe et al have reported inaccuracies in the knowledge of resident gynaecologists regarding outcomes post NSV, such as altered functioning of testes, impaired ejaculation and increased risk of prostate cancer. $^{12}$ Some initial concerns among providers regarding vasectomy and prostate cancer, testicular cancer, autoimmune diseases and cardiovascular diseases have also been reported in a study by Shih et al. ${ }^{7}$ However, since then, all of these associations have been proven to be false. ${ }^{14-17}$ Female gynaecologists in the present study appeared reluctant to undergo training in $\mathrm{NSV}$, the reason being their perception that their male colleagues would be more comfortable performing NSV and a man would be more comfortable getting NSV done from a male gynaecologist. Also, it was felt that few men would approach a female gynaecologist even to discuss NSV. This gender-related attitude and perceived bias has 
also been highlighted by Char et al in their study on multipurpose workers in the community. Their study has highlighted difficulties experienced by female health care workers in having a one-to-one discussion with men regarding contraception. ${ }^{13}$ Similarly, Ebeigbe et al have also found that psychological and sociocultural reasons deterred gynaecologists from advising NSV. ${ }^{12}$ Authors believe that practice of NSV is a direct reflection of knowledge and attitude towards NSV. Present study has shown that gynaecologists preferred to refer a couple willing for NSV elsewhere or preferred to advise female sterilisation. Authors strongly believe that this practice stems from inadequate knowledge about the NSV and lack of surgical skills required, as training in NSV is neither a part of undergraduate medical education nor post-graduate curriculum in Gynaecology.

However, both these factors are amenable to change, if so desired. The fact that majority of the gynaecologists displayed a positive attitude by showing willingness to undergo training in NSV, is certainly encouraging. It leads us to believe that this change can be brought about by appropriate intervention in the form of capacity building of gynaecologists.

\section{Strengths and limitations}

This was a city-wide survey. Authors received a preliminary response rate of $71 \%$ which is a fairly adequate representative sample. Few studies in the past have included responses from community health workers, but none have interviewed gynaecologists. Since the interviews were administered and completed in the presence of the data collector, authors are fairly certain to have received truthful responses. Although the consenting gynaecologists were assured of confidentiality regarding their identities, authors cannot deny the fact that some responders might have modified their answers to deem "acceptable".

\section{CONCLUSION}

Gynaecologists in the study sample had less awareness and inadequate knowledge about NSV, especially about post-NSV counselling. Large majority were not trained in performing NSV; however, a majority expressed willingness to undergo training if offered an opportunity. Common preferred practice was of referring the couple elsewhere or advising female sterilisation. Authors feel that including surgical skill training in NSV at the level of post-graduate medical education in relevant surgical fields could go a long way in bringing about positive change in the current scenario. Male gynaecologists appear best suited to undergo training in NSV skills. Training male gynaecologists could facilitate an increase in the uptake of NSV among eligible couples. Development and effective implementation of continued, short, skill-based training courses in NSV could help update the knowledge and thereby change the attitude and practice of gynaecologists in this field.

\section{ACKNOWLEDGMENTS}

Authors would like to thank all the gynaecologists who spared their valuable time for participating in the survey. Authors are grateful to research assistants Ankita Sharma, Sonal Kamble and Prachi Awalaskar and data collectors Ranjeet Kudwe, Arya Lambe, Geetanjali Savekar and Eknath Thongire for data collection and entry.

Funding: The study was funded by Deenanath Mangeshkar Hospital and Research Centre (DMHRC), Pune.

Conflict of interest: None declared

Ethical approval: The study was approved by the Institutional Ethics Committee on December 23rd 2015 (2015_Dec_GG_182).

\section{REFERENCES}

1. Bhuyan K, Ali I, Barua SJ. Role of No Scalpel Vasectomy in Male Sterilisation. 2012;74(4):284-7.

2. Bhuyan K, Ali I, Sarma G, Das U. No Scalpel Vasectomy (NSV) with Ligation and Excision: A Single Centre Experience. Indian Journal of Surgery. 2015;77(3):1038-40.

3. Li L, Shao J, Wang X. Percutaneous no-scalpel vasectomy via one puncture in China. Urol $\mathrm{J}$. 2014;11(2):1452-6.

4. Scott B, Alam D, Hopkins J, Raman S. The RESPOND Project Study Series: Contributions to Global Knowledge Factors Affecting Acceptance of Vasectomy in Uttar Pradesh: Insights from Community-Based, Participatory Qualitative Research Options PEER Unit Consultant, Options UK. 2011

5. Shih G, Dubé K, Dehlendorf C. "We never thought of a vasectomy": a qualitative study of men and women's counseling around sterilisation. Contracep. 2013;88(3):376-81.

6. Sood A, Pahwa P. Vasectomy : a study of attitudes, beliefs, knowledge and practices among literate men in Punjab, India. 2014;3(2):418-23.

7. Shih G, Zhang Y. Bringing Men to the Table: Sterilisation Can Be for Him or for Her. Clin Obstet Gynecol. 2014;57(4):731-40.

8. Rajoura O, Meena G, Kaza R, Bhasin S. Acceptability of No-scalpel Vasectomy at a male family welfare centre in Delhi. J Fam Welf. 2003;49(2):10-3.

9. International Institute for Population sciences. National Family Health Survey - 4, 2015-16. District Fact Sheet Pune. 2015; Available at : http://rchiips.org/NFHS/FCTS/MH/MH_FactSheet_5 21_Pune.pdf

10. International Institute for Population Sciences. National Family Health Survey - 4, 2015-2016--India Fact Sheet. Available at: http://www.rchiips.org/nfhshttp://www.iipsindia.org

11. Mahapatra S, Narula C, Kalita TJ, Thakur CP, Mehra R. Assessment of knowledge and perception 
regarding male sterilisation (Non-Scalpel Vasectomy) among community health workers in Jharkhand, India. Indian J Community Heal. 2014;26(4):428-33.

12. Ebeigbe PN, Igberase GO, Eigbefoh J. Vasectomy: a survey of attitudes, counseling patterns and acceptance among Nigerian resident gynaecologists. Ghana Med J. 2011;45(3):101-4.

13. Char A, Saavala M, Kulmala T. Provider bias or organizational limitations? Female and male health care workers' interaction with men in the reproductive health programmes in rural central India. J Fam Welf. 2011;57(2):1-11.

14. Dersimonian R, Clemens J, Spirtas R, Perlman J. Vasectomy and prostate cancer risk: Methodological review of the evidence. $J$ Clin Epidemiol. 1993;46(2):163-72.
15. Holt SK, Salinas CA, Stanford JL. Vasectomy and the risk of prostate cancer. J Urol. 2008;180(6):256578.

16. Moller H, Knudsen LB, Lynge E. Risk of testicular cancer after vasectomy: cohort study of over 73,000. BMJ. 1994;309:295-9.

17. Goldacre MJ, Wotton CJ, Seagroatt V, Yeates D. Cancer and cardiovascular disease after vasectomy: an epidemiological database study. Fertil Steril. 2005;84(5):1438-43.

Cite this article as: Godbole GP, Oka GA. No scalpel vasectomy: a cross-sectional study of knowledge, attitude and practice of gynaecologists. Int J Reprod Contracept Obstet Gynecol 2019;8:1149-54. 